\title{
Agôn
}

Revue des arts de la scène

Critiques | Saison 2014-2015

\section{Intérieur de Maurice Maeterlinck, mise en scène de Claude Régy}

Silence, on joue

\section{Caroline Châtelet}

\section{CpenEdition}

Journals

Édition électronique

URL : http://journals.openedition.org/agon/3104

DOI : 10.4000/agon.3104

ISSN : 1961-8581

Éditeur

Association Agôn

Référence électronique

Caroline Châtelet, «Intérieur de Maurice Maeterlinck, mise en scène de Claude Régy », Agôn [En ligne], Critiques, mis en ligne le 26 septembre 2014, consulté le 23 septembre 2020. URL : http://

journals.openedition.org/agon/3104; DOI : https://doi.org/10.4000/agon.3104

Ce document a été généré automatiquement le 23 septembre 2020.

Association Agôn et les auteurs des articles 


\section{Intérieur de Maurice Maeterlinck, mise en scène de Claude Régy}

Silence, on joue

Caroline Châtelet

\section{RÉFÉRENCE}

Intérieur de Maurice Maeterlinck, mise en scène de Claude Régy

Maison de la Culture du Japon à Paris, du 9 au 27 septembre (spectacle en japonais surtitré en français). Spectacle programmé dans le cadre de la $43^{e}$ édition du Festival d'Automne

1 À l'entrée des collections du Musée des Beaux-Arts de Nancy, il y a quelques années, un petit panneau listant diverses interdictions à l'attention des visiteurs stipulait de «ne pas rire». Relevant de l'arbitraire rigide plus que de la démarche justifiée, cette consigne éveillait chez moi un agacement inquiet, qui influait sur la visite à venir. Il en va ainsi du rapport aux œuvres : les circonstances de leur découverte sont des moments aussi fragiles que privilégiés. À vouloir trop les accompagner ou les diriger, les structures de diffusion - ou les artistes - brouillent plus qu'elles n'en facilitent la réception. Débuter une critique d'un spectacle par une telle digression peut sembler étrange, insister sur ce qui ne relève que d'un déroulé a priori anecdotique, singulier. Mais c'est méconnaître le très précis protocole entourant la mise en scène par Claude Régy avec des comédiens japonais d'Intérieur de Maurice Maeterlinck. Là, avant de pénétrer dans la salle, les spectateurs se voient signifié - par bande sonore l'obligation de garder le silence, en raison du «caractère particulier» du spectacle. Maintenu jusqu'au début de la représentation, scrupuleusement rappelé par les ouvreurs, ce silence installe une solennité pesante, étouffante, qui se prolongera toute la pièce. Paradoxalement, si cette façon (infantilisante) de policer le public agace, irrite, elle résonne étrangement avec le propos dramatique d'Intérieur. Lorsque le spectacle débute, une fillette est morte noyée et deux hommes, un vieillard et un étranger, 
arrivent devant la maison de ses parents pour leur apprendre la nouvelle. Il faudra toute la pièce pour que le vieil homme se décide à rompre la sérénité du foyer. C'est de cela, cette confrontation entre l'intérieur chaleureux nimbé d'un blanc laiteux où déjà semble sourdre une inquiétude et l'extérieur glacial, bleuté, où bientôt tout les villageois se retrouveront dont il est question. De la connaissance de la mort qui les gagnera tous mais qui, pour l'heure, n'atteint pas encore l'intérieur familial. À l'aune de cette dévastation qui s'annonce, le «caractère particulier " évoqué précédemment prend un autre sens. Nous, spectateurs, sommes du côté de ceux qui savent. Tandis que c'est en fond de scène que nous voyons les parents et les sœurs de la morte vaquer à leurs occupations (le petit frère dormant tranquillement), c'est à l'avant-scène que les deux hommes - et nous avec - les observent. Lumières ouatées de douceur pour la maison, glaciales pour l'extérieur. Pour autant, si la scénographie signée Salladyn Khatir et les lumières de Rémi Godfroy, composent avec subtilité les différents espaces, les personnages y évoluent de la même façon. Gestes volontairement lents, paroles excessivement décomposées, tout se fait dans une lenteur démesurée, jusqu'à l'apparition et la disparition des surtitres. Façon, peut-être, de rappeler par cette désincarnation que la pièce était lors de son écriture en 1894 destinée au théâtre de marionnettes, manière d'approcher l'univers du Butô - danse marquée par la lenteur -, ce choix est aussi celui d'un metteur en scène qui ne cesse d'explorer les possibilités de ralentissement du jeu. Si ce tempo souligne le statisme des situations propres au théâtre de Maeterlinck, ses états d'attente infinis hantés par la mort, une telle interprétation crée également un écart entre scène et salle. Accentué par la langue (le japonais) et par le choix de Claude Régy de réduire les surtitres au strict minimum, l'écart de compréhension se creuse jusqu'à devenir gouffre. En dépit de la beauté esthétique, de l'unité formelle et de la pertinence de l'ensemble, la pesanteur prend le dessus sur la beauté sublime. Certes, on sent la connaissance intime de l'œuvre et de l'auteur - Régy ayant monté plusieurs pièces de Maeterlinck au cours de sa vie, et ayant déjà mis en scène Intérieur en 1985. Sauf qu'à vouloir tout maîtriser, du silence jusqu'aux surtitres - là où les laisser in extenso aurait permis au spectateur de choisir de les lire - le metteur en scène expurge le spectacle de toute sensation et pulsation de vie. La perfection est là, mais lorsqu'elle s'accompagne comme ici d'une volonté de verrouiller de façon univoque les conditions de réception du public, elles en viennent à faire écran à l'œuvre. Naît alors le sentiment d'assister à une forme aboutie, parfaite, qui paradoxalement n'a pas besoin des spectateurs. Ou qui se plaît à penser à leur place, en oubliant que la découverte d'un spectacle est une expérience intime. 
Intérieur, de Maurice Maeterlinck

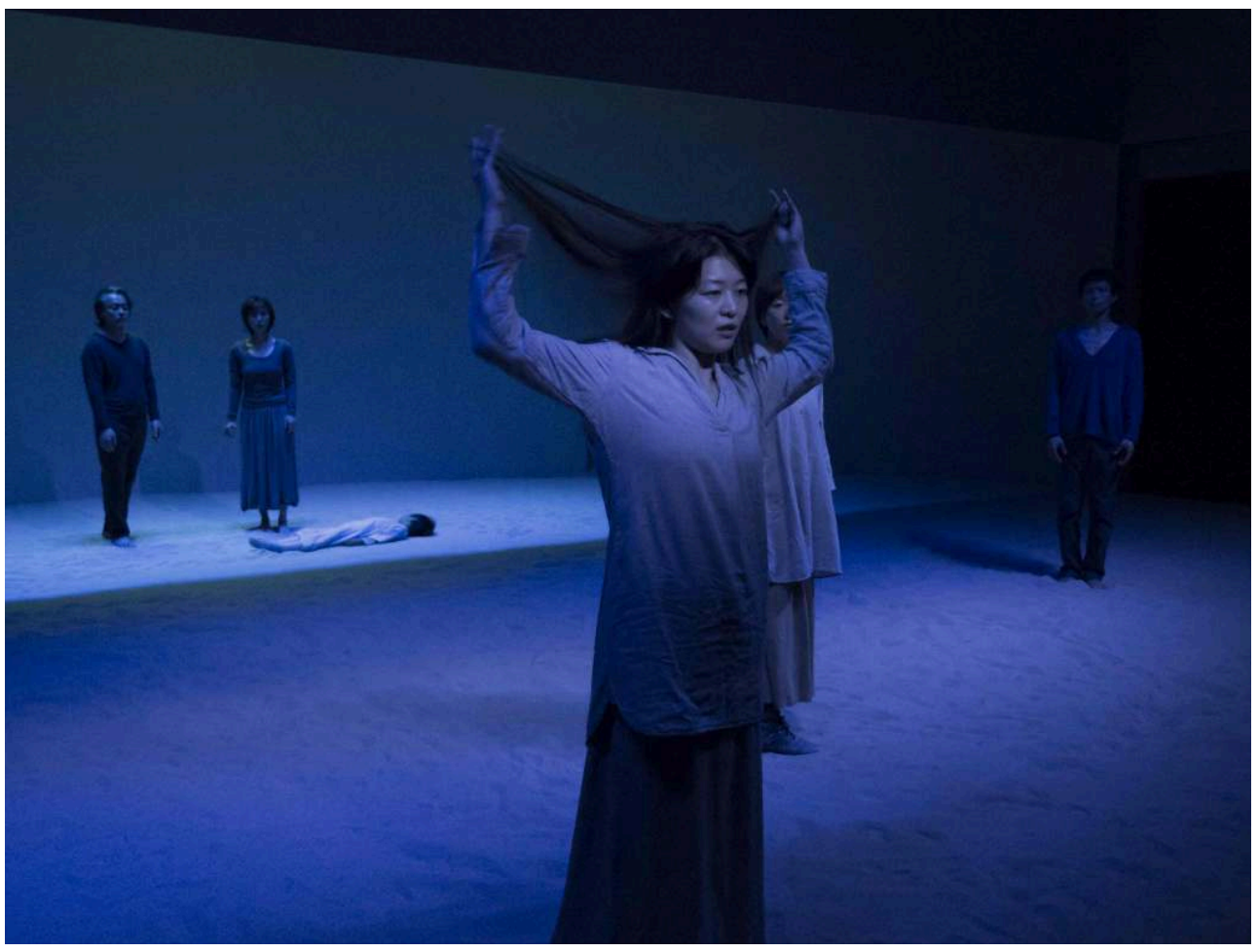

Mise en scène de Claude Régy

(c) Koichi Miura 